\title{
IS HIGHER-QUALITY LAND DEVELOPED EARLIER?
}

\author{
Juan Carlos Lopez*and Richard Arnott ${ }^{\dagger}$ \\ JEL Codes: R14, R31
}

Keywords: Land Use Patterns, Housing Supply and Markets

April 24, 2018

*Department of Economics, University of Denver, Denver CO 80208 juancarlos.lopez@du.edu

${ }^{\dagger}$ Department of Economics, University of California, Riverside CA 92506 richard.arnott@ucr.edu 


\begin{abstract}
This paper addresses the question: Is higher-quality land developed earlier? To answer this question, the paper applies comparative static analysis to the ArnottLewis model of the transition of land from agricultural to urban use. Four dimensions of land quality are considered: agricultural fertility, land preparation costs, structure construction costs, and amenities. It is shown that: i) an increase in agricultural fertility increases structural density and delays development; ii) a decline in land preparation cost reduces structural density and hastens development; iii) both an increase in amenities and a decrease in structure construction costs normally hasten development, but in anomalous cases can delay development. The paper presents two numerical examples illustrating these anomalies, and explains them.
\end{abstract}




\section{Introduction}

In a typical introductory lecture in land economics, a distinction is made between the Ricardian model of land use, rent and value and the corresponding von Thünen model. The Ricardian model focuses on the intrinsic properties of land, including fertility and natural amenities, which may be referred to collectively as "land quality". The von Thünen model, in contrast, focuses on differences in accessibility. Courses in urban economics focus on the monocentric city model, which extends the von Thünen model to the urban context. The monocentric model has been analyzed exhaustively (and some would argue exhaustingly). Ricardian differences in land are discussed, and indeed feature prominently in hedonic analysis. Remarkably, however, it appears that Ricardian differences in land have not been systematically incorporated into the monocentric city model. The aim of this paper is to at least partially remedy this oversight by addressing the question: "Is higher-quality land developed (in urban use) earlier?" The answer to the question depends, of course, on what is meant by land quality. We consider four dimensions of land quality: fertility, natural amenities, land preparation costs (so that servicing of the land is cheaper on higher quality land), and structure construction costs (so that structures are cheaper to construct on higher quality land).

There are static and dynamic variants of the monocentric city model. In the more familiar static variant, structures are treated as mobile and perfectly malleable. A parcel of land is in urban use if its rent in urban use exceeds its agricultural rent, and its floorarea ratio or structural density is determined by its urban rent. Over time, as the urban rent at a particular location increases, structural density increases. While we address the paper's question in the context of the static variant of the monocentric city model at the end of the paper, it is not the paper's focus. Instead, we focus on a dynamic variant of the monocentric city model in which structures are durable. In this situation, the owner of a parcel of land that has not yet been developed in urban use faces the decisions of when and at what structural density to convert the parcel to urban use. To simplify the model as much as possible, we make the assumption that structures are immutable and indestructible (so that, when a site is developed, the structure that is built on the site cannot be altered) and of constant quality. Furthermore, in our analysis we consider 
parcels that are equally accessible. The answers to the paper's question can then be provided by comparative static analysis applied to the Arnott and Lewis (1979) model of the transition of land to urban use.

Intuitively, the answer depends on what dimension of land quality is considered. One obvious intuition is that, ceteris paribus, parcels with lower fertility are developed earlier since the opportunity cost of their being developed is lower. Another obvious intuition is that parcels for which the marginal cost of construction is higher are developed either later or at lower density or both. The durability of structures makes the comparative statics result more complicated because the land quality affects two margins of choice: the timing and the density of development. How those two margins interact may depend in quite a complicated way on factors such as the interest rate, the growth rate of rents, and the elasticity of substitution between land and capital in the production of structures.

In the urban and regional economics literature there has been some recognition that land heterogeneity plays a role in determining urban spatial structure. Burchfield et al. (2006) use satellite data on US metropolitan areas to explore differences in sprawl across regions between 1976-1992. As part of their set of explanatory variables they consider the effect of heterogeneity in temperature, physical terrain and access to aquifers. The authors conclude that physical geography accounts for 25 percent of the variation in sprawl over US metropolitan areas. Saiz (2010) explores how variation in developable land due to geographic constraints across US metropolitan areas affects housing supply elasticities. He finds that land-constrained cities have significantly lower supply elasticities and higher housing prices than cities with a greater availability of developable land. In a different vein, Irwin and Bockstael (2002) consider how the development decision for a parcel of land in a current time period is influenced by spatial externalities associated with the land use decisions from neighboring plots in previous periods. The authors develop a dynamic model of interacting agents which yields a more fragmented development pattern in exurban areas than would be predicted by the standard monocentric model.

Section 2 presents the dynamic model with immutable and indestructible structures. Section 3 provides the results of the comparative static exercises for different forms of land quality. Section 4 remarks on the previous three sections. Section 5 treats the easier 
but less realistic static model. And section 6 concludes.

\section{The Dynamic Model}

The dynamic model is a variant of the Arnott-Lewis model. A profit-maximizing landowner decides when and at what density to convert a unit area of land he owns from agricultural to urban use, in the absence of zoning restrictions. To simplify, we assume that the interest rate, the growth rate of urban rent (per unit floor area), and the agricultural rent remain constant over time. Furthermore, we ignore the quality dimension of structures, including depreciation. Finally, we augment Arnott-Lewis to allow for (fixed) land preparation (or servicing) costs. The component of land servicing costs that increases in structural density is treated through the construction cost function.

We employ the following notation:

$s \quad$ structural density (or floor-area ratio)

T timing of development

$q \quad$ quality of land, whose interpretation varies depending on the type of quality differentiation being considered

$S(s, q) \quad$ current floor rent per unit area of land, which depends on $s$ and on $q$ only when $q$ represents natural amenities

$r \quad$ interest/discount rate

$g \quad$ growth rate of floor rent

$C(s, q) \quad$ current structure construction cost per unit area of land, which depends on $s$ and on $q$ only when $q$ represents elements of the land that affect structure construction costs

$L(q) \quad$ current land preparation (servicing) cost per unit area of land, which depends on $q$ only when $q$ represents elements of the land that affect land preparation costs

$R(q) \quad$ agricultural rent, which depends on $q$ only when $q$ represents agricultural fertility

$\hat{\pi}(s, T, q)$ present value of profit per unit area of land

Note that an improvement in natural amenities may affect floor rent differently on different floors of a building; for example, a view of the ocean may be visible for floors 
above a certain level but not below it. Similarly, an improvement in land quality may affect construction costs differently for different floors; for example, bedrock may have no effect on the construction costs for buildings below a certain floor-area ratio but reduce construction costs for building above that floor area.

The developer's discounted profit is

$$
\hat{\pi}(s, T, q)=\left[\frac{S(s, q)}{(r-g)}\right] e^{-(r-g) T}-\left[(C(s, q)+L(q)] e^{-r T}-\left[\frac{R(q)}{r}\right]\left(1-e^{-r T}\right) .\right.
$$

The first term on the right-hand side is the discounted floor rent from the land after it is developed. The second term is discounted construction costs and land preparation costs. The third term is the discounted agricultural rent from the land before it is developed.

The first-order condition with respect to structural density is

$$
\hat{\pi}_{s}(s, T, q)=\left[\frac{S_{s}(s, q)}{(r-g)}\right] e^{-(r-g) T}-C_{s}(s, q) e^{-r T}=0 .
$$

The first term on the right-hand side is the discounted marginal revenue from structural density, and the second term is the discounted marginal cost.

The first-order condition with respect to development time is

$$
\hat{\pi}_{T}(s, T, q)=-S(s, q) e^{-(r-g) T}+r[C(s, q)+L(q)] e^{-r T}+R(q) e^{-r T}=0 .
$$

The first term on the right-hand side is the discounted marginal cost of postponing development one period, which is the discounted structure rent forgone. The sum of the second and third terms is the discounted marginal benefit of postponing development one period, which equals the discounted saving from postponing construction and land preparation costs for one year plus the discounted agricultural rent.

Note that $e^{-r T}$ appears in all the terms above. To simplify the algebra, we eliminate it from the two first-order conditions. The economic interpretation of doing so is that the profit-maximizing program is the same at whatever point in time profits are measured. Defining $\pi(s, T, q)$ to be the value of profit at development time, the two first-order 
conditions may be written as

$$
\begin{gathered}
\pi_{s}(s, T, q)=\left[\frac{S_{s}(s, q)}{(r-g)}\right] e^{g T}-C_{s}(s, q)=0, \\
\pi_{T}(s, T, q)=-S(s, q) e^{g T}+r[C(s, q)+L(q)]+R(q)=0 .
\end{gathered}
$$

To simplify notation, we define $B(s, q) \equiv r[C(s, q)+L(q)]+R(q)$, to be the contemporaneous benefit from postponing development for a unit of time, which equals the interest on the construction and land preparation costs, plus the agricultural rent from land. The first-order condition with respect to $T$ can then be rewritten as

$$
\pi_{T}(s, T, q)=-S(s, q) e^{g T}+B(s, q)=0 .
$$

Sufficient conditions for (4) and (5) to describe a local profit maximum are that $\pi_{s s}(s, T, q)=S_{s s}(s, q) e^{g T} /(r-g)-C_{s s}(s, q)<0, \pi_{T T}(s, T, q)=-g[S(s, q)] e^{g T}<0$, and $\pi_{s s}(s, T, q) \pi_{T T}(s, T, q)-\pi_{s T}(s, T, q) \pi_{T s}(s, T, q)>0$. The first condition is that there are decreasing marginal profits to constructing floor area. The second condition is that rents are growing. Since $\pi_{s T}(s, T, q)=\pi_{T s}(s, T, q)=g\left[S_{s}(s, q) /(r-g)\right] e^{g T}>0$, the third condition may be rewritten as $\pi_{T T}(s, T, q) / \pi_{T s}(s, T, q)=(d s / d T)_{F O C_{s}}<(d s / d T)_{F O C_{T}}=$ $\pi_{s T}(s, T, q) / \pi_{s s}(s, T, q)$, which states that in $T-s$ space, the slope of the first-order condition with respect to $T$ is steeper than that with respect to $s$ (both slopes are positive). Were it not for $R(q)$, the condition would have the economic interpretation that the elasticity of substitution between land and capital in the production of a structure is less than one. If the condition does not hold, the point at which the two first-order conditions intersect is a local minimum; profit can be increased either by building earlier at a lower density or building later at a higher density.

Figure 1 plots the two first-order conditions, $F O C_{s}$ and $F O C_{T}$, in $T-s$ space. Sufficient conditions for their point of intersection to characterize a local profit maximum are that the two first-order conditions be positively sloped, and that the first-order condition with respect to $T$ is steeper than that with respect to $s$. 


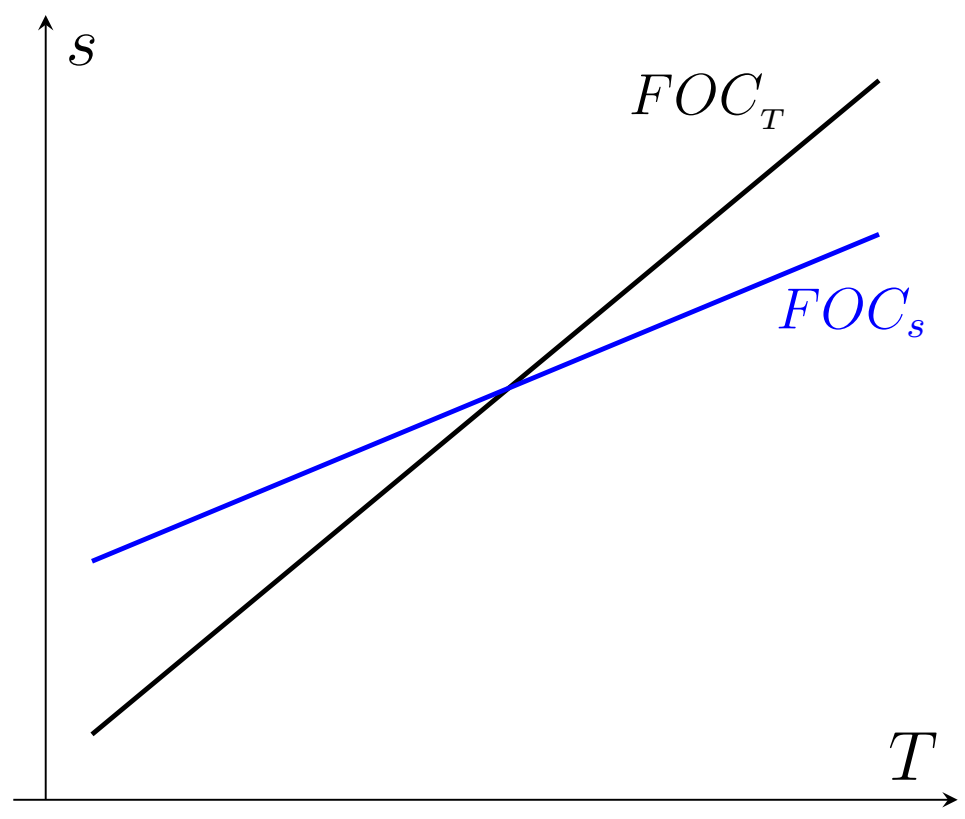

Figure 1: First-order conditions in $T-s$ space

\section{Comparative Static Analysis}

\subsection{Laying the groundwork}

We shall logarithmically differentiate (4) and (6). The advantage of logarithmic differentiation is that all terms are expressed in unitless quantities such as elasticities. Since the process of logarithmic differentiation is not covered in many of today's graduate programs, we proceed step by step. First, totally differentiate (4) and (6) with respect to $s, T$, and $q$, holding the parameters $r$ and $g$ constant, where to simplify notation we suppress the arguments of the functions,

$$
\begin{gathered}
{\left[\frac{S_{s s}}{(r-g)} e^{g T}-C_{s s}\right] d s+\left[\frac{g S_{s}}{(r-g)} e^{g T}\right] d T=\left[-\frac{S_{s q}}{(r-g)} e^{g T}+C_{s q}\right] d q} \\
\left.\left[\frac{g S_{s}}{(r-g)}\right] e^{g T}\right] d s+\left[-g S e^{-g T}\right] d T=\left[S_{q} e^{-g T}-B_{q}\right] d q
\end{gathered}
$$

and where use is made of the fact that $\pi_{T s}=-S_{s}(s, q) e^{g T}+B_{s}(s, q)=g S_{s}(s, q) e^{g T} /(r-$ $g)=\pi_{T s}$. Next divide each term by the corresponding term in the equation that was totally differentiated. For example, to obtain $C_{s s}$ in the first equation, the term $C_{s}$ was differentiated. Using the relationships derived from the first-order conditions in (4) and 
(6) the two equations become

$$
\begin{gathered}
{\left[\frac{S_{s s}}{S_{s}}-\frac{C_{s s}}{C_{s}}\right] d s+[g] d T=\left[-\frac{S_{s q}}{S_{s}}+\frac{C_{s q}}{C_{s}}\right] d q,} \\
{\left[\frac{g}{r-g} \frac{S_{s}}{S}\right] d s+[-g] d T=\left[\frac{S_{q}}{S}-\frac{B_{q}}{B}\right] d q,}
\end{gathered}
$$

which may be rewritten as

$$
\begin{gathered}
{\left[\frac{S_{s s} s}{S_{s}}-\frac{C_{s s} s}{C_{s}}\right] \hat{s}+[g] d T=\left[-\frac{S_{s q} q}{S_{s}}+\frac{C_{s q} q}{C_{s}}\right] \hat{q},} \\
{\left[\frac{g}{r-g} \frac{S_{s} s}{S}\right] \hat{s}+[-g] d T=\left[\frac{S_{q} q}{S}-\frac{B_{q} q}{B}\right] \hat{q},}
\end{gathered}
$$

where $\hat{s}=d s / s$, etc. Now,

$$
\frac{B_{q} q}{B}=\left[\frac{R_{q} q}{R}\right]\left[\frac{R}{(r(C+L)+R)}\right]+\left[\frac{r\left(C_{q}+L_{q}\right) q}{(r(C+L)}\right]\left[\frac{r(C+L)}{(r(C+L)+R)}\right] .
$$

Define

$$
\theta \equiv R /(r(C+L)+R)
$$

so that

$$
\frac{B_{q} q}{B}=\left[\frac{R_{q} q}{R}\right] \theta+\left[\frac{r\left(C_{q}+L_{q}\right) q}{r(C+L)}\right](1-\theta) .
$$

$\theta$ is the share of that cost of postponing development one period that is agricultural rent. Then (12) above may be written as

$$
\left[\frac{g}{r-g} \frac{S_{s} s}{S}\right] \hat{s}+[-g] d T=\left[\frac{S_{q} q}{S}-\left[\frac{R_{q} q}{R}\right] \theta-\left[\frac{\left(C_{q}+L_{q}\right) q}{(C+L)}\right](1-\theta)\right] \hat{q}
$$

Rewrite (11) and (15) using elasticity notation (with $E_{a: b}$ denoting the elasticity of $a$ with respect to $b$ ) which yields

$$
\begin{aligned}
& {\left[E_{S_{s: s}}-E_{C_{s: s}: s}\right] \hat{s}+[g] d T=\left[E_{S_{s}: q}-E_{C_{s}: q}\right] \hat{q},} \\
& {\left[\frac{g}{r-g} E_{S: s}\right] \hat{s}+[-g] d T=\left[E_{S: q}-E_{R: q} \theta-E_{(C+L): q}(1-\theta)\right] \hat{q} .}
\end{aligned}
$$


Putting the set of linear equations in matrix form we then have

$$
\left[\begin{array}{ll}
U & V \\
X & Y
\end{array}\right]\left[\begin{array}{c}
\hat{s} \\
d T
\end{array}\right]=\left[\begin{array}{l}
W \\
Z
\end{array}\right] \hat{q},
$$

where

$$
\begin{aligned}
& U=E_{S_{s}: s}-E_{C_{s}: s}<0, \\
& V=g>0, \\
& W=-E_{S_{s}: q}+E_{C_{s}: q} \gtreqless 0, \\
& X=\frac{g}{r-g} E_{S: s}>0, \\
& Y=-g<0, \\
& Z=E_{S: q}-\theta E_{R: q}-(1-\theta) E_{(C+L): q} \gtreqless 0 .
\end{aligned}
$$

Finally, solving out the pair of simultaneous linear equations using Cramer's Rule gives

$$
\begin{gathered}
\frac{\hat{s}}{\hat{q}}=\frac{(W Y-V Z)}{(U Y-V X)}, \\
\frac{d T}{\hat{q}}=\frac{(U Z-W X)}{(U Y-V X)} .
\end{gathered}
$$

For Eqs. (19)-(24) we have indicated the signs of the various terms. The signs of $W$ and $Z$ depend on elasticities with respect to land quality, which depend on the nature of land quality, and are therefore a priori ambiguous $(\gtreqless 0)$. Since we are considering land that has not yet been developed at the present time, which we have normalized to zero, $T$ is positive. Finally, we assume that, as functions of structural density, there are increasing marginal costs to construction, $E_{C_{s}: s}>0$. 
Define

$$
\begin{aligned}
\Delta & =U Y-V X \\
& =g\left[-\left(E_{S_{s: s}}-E_{C s: s}\right)-\frac{g}{r-g} E_{S: s}\right] .
\end{aligned}
$$

The third of the second-order conditions requires that $\Delta$ be positive.

An increase in land quality causes either or both of the first-order conditions, (4) and (5), to shift. The nature of land quality determines which of the first-order conditions is shifted and by how much. This is the subject of the subsections that follow. We consider only one type of land quality at a time.

\subsection{An improvement in land quality corresponds to an increase in agricultural fertility}

This is the simplest case to treat. Since quality is an ordinal concept, we may cardinalize it as we wish. Here the simplest cardinalization is to measure land quality as agricultural fertility, i.e. $R(q)=q$. In which case $E_{R: q}=1$. Since only one type of land quality is considered at a time, $E_{S: q}=E_{C_{s}: q}=E_{(C+L): q}=0$. We then obtain

$$
\begin{aligned}
\frac{\hat{s}}{\hat{q}} & =\frac{\theta g}{\Delta}>0, \\
\frac{d T}{\hat{q}} & =-\frac{\theta\left[E_{S_{s}: s}-E_{C_{s: s}}\right]}{\Delta}>0 .
\end{aligned}
$$

With respect to Fig. 1, an increase in agricultural fertility has no effect on $F O C_{s}$ and causes $F O C_{T}$ to shift to the right (since holding structural density fixed, profitmaximizing development time increases). Thus, more fertile land is developed later and at higher density, as argued earlier. 


\subsection{An improvement in land quality corresponds to a decrease in the fixed cost of servicing land per unit area}

In this section we employ a different normalization of land quality in which land servicing cost is inversely proportional to quality, i.e. $L(q)=L / q$. Thus, $W=0$ and $Z=-(1-\theta) E_{(C+L): q}=-(1-\theta)[d(C+L(q)) / d q] q /(C+L)=(1-\theta) L /(C+L)$. We obtain:

$$
\begin{aligned}
& \frac{\hat{s}}{\hat{q}}=-\frac{g(1-\theta) L}{(C+L)} \frac{1}{\Delta}<0, \\
& \frac{d T}{\hat{q}}=-\frac{(1-\theta) L\left(E_{S_{s}: s}-E_{C_{s}: s}\right)}{(C+L)} \frac{1}{\Delta}<0 .
\end{aligned}
$$

With respect to Fig. 1, a decrease in (fixed) land servicing costs has no effect on $F O C_{s}$ and causes $F O C_{T}$ to shift to the left (since holding structural density fixed, profit-maximizing development time decreases). Thus, a decrease in land servicing costs causes development to occur earlier and at lower density.

\subsection{An improvement in land quality corresponds to a decrease in construction costs}

The first-order condition with respect to structural density depends on marginal construction cost, while the timing condition depends on total or average construction cost. Thus, we should expect that the manner in which a decrease in construction costs affects development timing and density depends on the way in which a marginal increase in quality affects the construction cost function. For example, higher-quality land may correspond to land that is less prone to flooding or to land that is further from a seismic fault, and the change induced in the cost-minimizing construction technology may be quite different in the two situations. One might cause a proportional change in construction cost at all other densities, while the other might cause a decrease in construction cost only for structural densities above a certain level.

We shall first present the intuition for our results, drawing on Figure 1. We shall then work through the algebra, and present an example in which an improvement in land 
quality results in later development. This result is of particular interest since it runs counter to most of our results (higher land quality corresponding to greater agricultural fertility being the exception) in which the improvement in land quality results in earlier development by decreasing the marginal benefit from postponing development.

A decrease in construction costs causes the first-order condition with respect to development timing to shift left and the first-order condition with respect to structural density to shift up. As noted above, the amount by which the timing first-order condition shifts left depends on how land quality improvement affects average cost, while the amount by which the density condition shifts up depends on how land quality improvement affects marginal cost. In the algebra that follows, we shall present two main results. The first provides a point of reference. In a particularly simple variant of the model in which agricultural rent and land improvement costs are zero, a land quality improvement that results in an equiproportional reduction in construction costs at all densities results in earlier development with no change in density. The second result is that a land quality improvement that reduces marginal construction cost proportionally more than it reduces average construction cost can result in later development.

The intuition is as follows. Consider two neighboring sites that differ only in land quality. Suppose that it is profit maximizing to develop site 110 years from now at 20 stories. Site 2 differs from site 1 in having bedrock underneath. We consider two situations. In the first, the bedrock foundation results in an equiproportional reduction in construction costs at all densities. For $F O C_{T}$, holding structural density fixed, lower construction costs reduce the benefit from postponing construction, encouraging earlier development. For $F O C_{s}$, holding development time fixed, lower construction costs reduce the marginal cost of density, encouraging development at higher density. In the reference situation in which construction costs for site 2 are lower than those for site 1 in the same proportion at all densities, the amount by which $F O C_{T}$ for site 2 lies to the left of that for site 1 relative to the amount by which $F O C_{s}$ for site 2 lies above that for site 1 is such that development on site 2 occurs at 20 stories as well but earlier than on site 1 .

Now modify the example so that the bedrock foundation permits the use of a construction technique that reduces construction costs only above 30 stories. Since $F O C_{s}$ 
depends on marginal cost, the bedrock foundation has no effect on $F O C_{s}$ below 30 stories, but above 30 stories causes $F O C_{s}$ to shift up discontinously. Since $F O C_{T}$ depends on average cost, having the bedrock foundation has no effect on $F O C_{T}$ up to 30 stories but above that causes its slope to increase (rather than to shift up discontinuously). For site 2 , there may then be two local maxima, and profit may be higher with construction at 30 rather than 20 stories. But rents ten years from now may not be sufficiently high to justify construction at the higher density, so that development is postponed.

We now turn to the algebra. Because of the type of land quality improvement being considered, $L_{q}=0$, so that $E_{(C+L): q}=C_{q} q /(C+L)=E_{C: q}(C /(C+L))$. In addition $W=E_{C_{s}: q}$ and $Z=-(1-\theta) E_{(C+L): q}$. Then

$$
\begin{aligned}
\frac{\hat{s}}{\hat{q}} & =g \frac{\left[-E_{C_{s}: q}+(1-\theta) E_{C: q} \frac{C}{(C+L)}\right]}{\Delta}, \\
\frac{d T}{\hat{q}} & =\frac{\left[-(1-\theta)\left(E_{S_{s}: s}-E_{C_{s}: s}\right) E_{C: q} \frac{C}{(C+L)}-\left(\frac{g}{r-g} E_{S: s}\right) E_{C_{s}: q}\right]}{\Delta} .
\end{aligned}
$$

We present two results. The first formalizes the argument presented above for the first situation. The second gives an example of the second situation in which an increase in land quality that lowers marginal construction costs more than average construction costs results in construction being delayed.

Result 1: If there are no land improvement costs (so that $L=0$ ), if agricultural rent is zero (so that $R=0$ ), and if higher-quality land corresponds to an an equiproportional reduction in construction costs for all levels of density (so that $C(s, q)=C(s) f(q)$, with $q>0, f>0$ and $\left.f^{\prime}<0\right)$ then $\hat{s} / \hat{q}=0$ and $d T / \hat{q}<0$.

Proof. Under the stated conditions, $E_{C: q}=E_{C_{s}: q}=f^{\prime} q / f$, so that (32) and (33) reduce to

$$
\begin{aligned}
\frac{\hat{s}}{\hat{q}} & =\frac{g\left(-E_{C_{s}: q}+E_{C: q}\right)}{\Delta}=0, \\
\frac{d T}{\hat{q}} & =\frac{-\left(E_{S_{s}: s}-E_{C_{s}: s}\right) E_{C: q}-E_{C_{s}: q}\left(\frac{g}{r-g} E_{S: s}\right)}{\Delta}=\left(f^{\prime} q / f\right) \frac{-\left(E_{S_{s}: s}-E_{C_{s}: s}\right)-\left(\frac{g}{r-g} E_{S: s}\right)}{\Delta} .
\end{aligned}
$$


Recalling that $\Delta=g\left[-\left(E_{S_{s}: s}-E_{C_{s}: s}\right)-\left(\frac{g}{r-g} E_{S: s}\right)\right]$, the expression for $d T / \hat{q}$ reduces to

$$
\frac{d T}{\hat{q}}=\frac{\left(f^{\prime} q / f\right)}{g}<0
$$

Thus, when $\Delta>0$, the improvement in quality causes profit-maximizing construction to be brought forward.

The last equation follows directly from the first-order conditions. Under the stated conditions, the first-order conditions remain satisfied if $e^{g T} / f(q)$ is equal to a constant. Total differentiation gives $g d T-\left(f^{\prime} / f\right) d q=0$ so that $d T / \hat{q}=\left(f^{\prime} q / f\right) / g$.

Result 2: If there are no land improvement costs (so that $L=0$ ), if agricultural rent is zero (so that $R=0$ ), if rent per unit floor area is independent of density (so that $S(s)=p s)$, and if higher land quality results in a reduction in construction costs that is proportionally higher at higher densities, then it may be profitable to develop higher quality land later.

Proof. The proof entails the construction of a numerical example. We assume a construction cost function of the form $C(s, q)=s^{b} e^{a s / q}$, where $a>0$ and $b>0$. This cost function has the property that an increase in land quality results in a greater proportional reduction in construction costs the higher is structural density (i.e., $\hat{C} / \hat{q}=-a s / q^{2}$ ). The partial derivatives of this cost function are

$$
\begin{aligned}
C_{s} & =C(b / s+a / q) \\
C_{s s} & =C_{s}(b / s+a / q)-C b / s^{2}=C\left((b / s+a / q)^{2}-b / s^{2}\right) \\
C_{q} & =-a s C / q^{2} \\
C_{s q} & =-a C / q^{2}-a s C_{s} / q^{2}=-\left(a C / q^{2}\right)(1+b+a s / q)
\end{aligned}
$$

We shall choose other parameters such at $s=1$ and $T=0$ at the optimum, and normalize such that $q=1$ in the base situation. Then at the base optimum $C_{s} / C=b+a$, $C_{s s} / C_{s}=\left((b+a)^{2}-b\right) /(b+a), C_{q} / C=-a$, and $C_{s q} / C_{s}=-a(1+b+a) /(b+a)$. 
Under the stated conditions, the first-order conditions are

$$
\begin{aligned}
& s: p e^{g T}-(r-g) C_{s}(s, q)=p e^{g T}-(r-g) s^{b} e^{a s / q}(b / s+a / q)=0, \\
& T:-p s e^{g T}+r C(s, q)=-p s e^{g T}+r s^{b} e^{a s / q}=0 .
\end{aligned}
$$

These conditions are satisfied at $q=s=1$ and $T=0$ if

$$
p-(r-g) e^{a}(b+a)=0, \quad-p+r e^{a}=0,
$$

and in particular with the parameters $p=r e^{a}$ and $(r-g)(b+a)=r$, which we assume to hold.

The example satisfies the second-order conditions that $\pi_{s s}<0$ and $\pi_{T T}<0$. To establish the Result, it remains to prove that $\Delta>0$ and $d T / \hat{q}>0$. Now, under the stated conditions, $E_{S: s}=1$ and $E_{S_{s}: s}=0$, so that $\Delta=g\left(E_{C_{s}: s}-g /(r-g)\right)$. Since $E_{C_{s}: s}=\left[(b+a)^{2}-b\right] /(b+a)$, from $(34), g /(r-g)=r /(r-g)-1=b+a-1$, it follows that $\Delta=g\left(E_{C_{s}: s}-g /(r-g)\right)=b+a-b /(b+a)-(b+a)+1=a /(a+b)>0$. Ву a similar line of reasoning

$$
\begin{aligned}
\frac{d T}{\hat{q}} & =\frac{\left[E_{C_{s}: s} E_{C: q}-E_{C_{s}: q}\left(\frac{g}{r-g}\right)\right]}{g\left(E_{C_{s}: s}-\frac{g}{r-g}\right)} \\
& =\frac{\frac{a}{a+b}\left((1+b+a) \frac{g}{r-g}-\left((b+a)^{2}-b\right)\right)}{g\left(\frac{a}{a+b}\right)} \\
& =\frac{\left(\frac{g}{r-g}-a\right)}{g},
\end{aligned}
$$

where use is made of the parameter restrictions in (34). It follows directly that if $a<$ $g /(r-g), d T / d \hat{q}>0$.

Consider an example in which $a=1$, and $g / r=2 / 3$ implying that $d T / \hat{q}=1 / g$. Suppose $g=0.02$, then a $10 \%$ improvement in land quality would result in construction occurring five years later. 


\subsection{An improvement in land quality corresponds to an increase in amenities}

Define the reference situation to occur when $S(s, q)=s p(q)$ so that the floor rent on all stories is the same, and an increase in amenities results in a uniform increase in the floor rent on all stories. In this reference situation, (25) and (26) reduce to

$$
\begin{aligned}
\frac{\hat{s}}{\hat{q}}= & g \frac{\left(E_{S_{s}: q}-E_{S: q}\right)}{\Delta}=0, \\
\frac{d T}{\hat{q}}= & \frac{\left[\left(E_{S_{s}: s}-E_{C_{s}: s}\right) E_{S: q}+E_{S_{s}: q}\left(\frac{g}{r-g} E_{S: s}\right)\right]}{\Delta} \\
& =\frac{\left(p^{\prime} q / p\right)\left[-E_{C_{s}: s}+\frac{g}{r-g}\right]}{\Delta}=-\frac{\left(p^{\prime} q / p\right)}{g}<0,
\end{aligned}
$$

with

$$
\Delta=g\left[-E_{S_{s}: s}+E_{C_{s}: s}-\frac{g}{r-g} E_{S: s}\right]=g\left[E_{C_{s}: s}-\frac{g}{r-g}\right] .
$$

Thus, with $\Delta>0$ the increase in amenities results in earlier development at unchanged density. These results have a straightforward explanation. In the above specification, an increase in amenities changes the developer's problem only in that the future is brought forward; it is profit maximizing for the developer to do exactly as he would have done before the amenity improvement, but earlier. In particular, $q$ and $T$ are related that such that $p(q) e^{g T}$ is constant, so that $d T / \hat{q}=-\left(p^{\prime} q / p\right) g$.

We now investigate whether, with the general specification of the rent function, $S(s, q)$, it is possible for an increase in amenities to result in a postponement of development. Intuitively for this to occur, the increase in amenities must increase rents disproportionately at higher density. Imagine a situation in which there are two sites, site 1 and site 2 . It is profit maximizing to develop site 1 at 20 stories today. Site 2 differs from site 1 only in that it has an unobstructed view of the mountains above 30 stories. Rents today however are not sufficiently high to justify constructing a building of this height. It may however be profit maximizing to delay development of site 2 until building above 30 stories is justified.

We assume a particular rentals function, and derive restrictions on the construction 
cost function such that an increase in amenities causes development to be delayed. The assumed form of the rentals function is $S(s, q)=m\left(s / q+s^{2} q^{2}\right)$, with $m>0$, and the parameters are such that, with $q=1$, the profit maximum occurs with $s=1$ and at $T=0$. Rent is higher on higher stories (at the profit maximum with $s=1, E_{S_{s}: s}=2 / 3$ ) and is proportionally higher the higher the level of amenity $\left(d E_{S_{s}: s} / d q>0\right)$. With this rentals function,

$$
\begin{aligned}
& E_{S: s}=\left(1 / q+2 s q^{2}\right) /\left(1 / q+s q^{2}\right), \\
& E_{S_{s}: s}=2 s q^{2} /\left(1 / q+2 s q^{2}\right), \\
& E_{S: q}=\left(-s / q+2 s^{2} q^{2}\right) /\left(s / q+s^{2} q^{2}\right), \\
& E_{S_{s: q}}=\left(-1 / q^{2}+4 q^{2}\right) /\left(1 / q+2 s q^{2}\right) .
\end{aligned}
$$

Substituting these elasticities, evaluated at $q=1$ and $s=1$, gives the following expression for $\Delta$ and the numerator of $d T / \hat{q}$, which we define as $N$, from (26):

$$
\begin{aligned}
& \Delta=-g\left(\left(\frac{2}{3}-E_{C_{s}: s}\right)+\frac{3}{2} \frac{g}{r-g}\right)=-g\left(\frac{2}{3}-E_{C_{s}: s}+\frac{3}{2} \frac{g}{r-g}\right), \\
& N=\left(\frac{1}{2}\left(\frac{2}{3}-E_{C_{s}: s}\right)+\frac{3}{2} \frac{g}{r-g}\right)=\frac{1}{2}\left(\frac{2}{3}-E_{C_{s}: s}+3 \frac{g}{r-g}\right) .
\end{aligned}
$$

Both $\Delta$ and $N$ must be positive for the second-order condition to be satisfied and for an increase in amenities to delay profit-maximizing development. Solving (37) and (38) for $\Delta>0$ and $N>0$ yields

$$
\frac{2}{3}+\frac{3}{2} \frac{g}{r-g}<E_{C_{s}: s}<\frac{2}{3}+3 \frac{g}{r-g}
$$

Consider the case where $g / r=1 / 2$, in which case $g /(r-g)=1$ and $13 / 6<E_{C_{s}: s}<22 / 6$. Suppose $E_{C_{s}: s}=3$, which falls in the appropriate range. This yields $d T / \hat{q}=2 /(5 g)$. With a rental growth rate of $2 \%$ then a $10 \%$ increase in amenities yields a development delay of 2 years. 


\section{$4 \quad$ Remarks}

1. We came to the question posed in the paper's title indirectly. Arnott was interested in the empirical validity of the Henry George Theorem. The static version of the Theorem is that, in an efficient metropolitan area (including the efficient population size), aggregate urban land rent and the revenue raised from the marginal cost pricing of urban public services just cover the costs of providing the efficient level of public services; thus, the single tax that would be needed to finance public services would be a confiscatory tax of urban land rent. The dynamic version of the Theorem is that, in an efficient metropolitan area, aggregate urban land value plus the discounted revenue raised from the marginal cost pricing of public services just cover the discounted costs of providing the efficient level of public services. Since metropolitan areas are not efficient, one should not expect the Henry George Theorem to hold exactly. Nonetheless, it is of interest to investigate the empirical magnitude of aggregate land values in a metropolitan area. Arnott had data, assembled by the Southern California Association of Governments (SCAG) from land registry records on the sales price, year of sale, and location and area of all vacant land parcels in the five-county Greater Los Angeles area, but no data on the Ricardian properties of the parcels, except for distance from the ocean. The data are sufficient to estimate a market land value surface for vacant land over the metropolitan area (Zhang and Arnott, 2015). Arnott posed this question: Is it sound to estimate the aggregate market value of all land, both vacant and developed, as the volume under this land value surface? Put alternatively, in a small geographic area, does the mean market value of vacant land per unit area provide an unbiased estimate of the mean market value of developed land per unit area? This is not the place to provide a detailed discussion of all the issues ${ }^{1}$. But one issue is whether, in a small geographic area, higher-quality land is systematically developed earlier than lower-quality land. If it is, then, in each small geographic area, the mean value of vacant land per unit area provides a systematic underestimate of the mean value of developed land per unit area. It was an investigation

$1 \quad$ Suffice it to say that three of the issues are zoning, the plattage effect (that, over each small geographic area, the value of land per unit area is higher for smaller than for larger lots), and the agglomeration benefits from proximity to other developed (and perhaps undeveloped) land values that are captured in land rents and values. 
of this issue that motivated this paper's analysis.

Arnott had another motivation for writing the paper. Land is an ideal tax base. A tax on land would not only be efficient, but would also likely have desirable distributional impacts. But given the propensity of taxpayers to appeal assessments, it is important to get accurate assessments of land values. Unfortunately, the analysis of this paper indicates that estimating the value of developed land from the sales prices of proximate vacant parcels is problematic, when, as is normally the case, higher quality land parcels get developed earlier.

2. We believe the model used to investigate the question that is the title of this paper, as well as our analysis of its properties are sound. However, the model provides a simplified description of reality, as indeed do all models, and should be regarded as providing a starting point for further, more sophisticated analyses. There are many ways in which the model can be enriched to improve its realism, including treating uncertainty (and along with it the option value component of vacant land) and risk aversion, zoning, depreciation of structures, taxes, structural quality, and redevelopment. Furthermore, two of the model's simplifying assumptions, that the growth rate of rents and the interest rate are constant over time, can be relaxed.

3. It is disappointing that the empirical literature in real estate economics has paid little attention to developers' decisions of when and at what density to build, since these decisions affect the properties of metropolitan real estate and construction cycles, and the impact of tax, land use, and other policy changes on them. The theory presented in this paper assumes that these decisions are determined completely by market forces (if there is zoning, then it is non-binding). If, at the other extreme, developers' construction timing and development decisions are fully determined by zoning regulations, then metropolitan real estate models should contain a module that endogenizes zoning regulations (the political economy of zoning).

4. The paper considered only one dimension of quality differentiation at a time. However, adjacent plots of land may differ in more than one dimension simultaneously. For example, if one site lies higher on a hillside than another, it will have a better view but at the same time its land preparation and construction costs may be higher. 


\section{The Static Model}

The static model of metropolitan land use is the monocentric city model. It has three dynamic interpretations. The first is that structures are non-durable, so that each day the landowner decides on structural density so as to maximize that period's profits based on current conditions; the second is that structures are durable but mobile, so that the landowner decides how much structure capital to rent every day; and the third is that the metropolitan area is in a steady-state, so that the economic cost of operating a unit area of land in urban use equals the opportunity cost of the land (the agricultural rent) and the durable capital (the cost of capital) ${ }^{2}$. In each of these interpretations, the landowner chooses whether to operate his land in agricultural use or in urban use, and if he chooses to operate it in urban use, he chooses structural density. The agricultural rent and the rent per unit floor area are based on market clearing in the location-specific markets, and the cost of capital is taken as exogenous. In keeping with the durable structures model, the cost of capital is taken to be the interest rate. Where the same notation is employed as in the previous section, conditional on operating his land in urban use, the landowner's profit-maximization problem is

$$
\max _{s} S(s, q)-r C(s, q)-r L(q)
$$

The first-order condition with respect to $s$ is

$$
S_{s}(s, q)-r C_{s}(s, q)=0
$$

Structural density is chosen such that the marginal revenue of structural density equals the marginal cost. Letting $s^{*}(q)$ be the profit-maximizing structural density, the urban land rent on land of quality $q$ is $U(q)=S\left(s^{*}(q), q\right)-r C\left(s^{*}(q)\right)-r L(q)$. The landowner operates his land in urban use if the urban land rent, $U(q)$, exceeds the agricultural land rent, $R(q)$, and in agricultural use if the inequality is reversed. Thus, land quality determines whether land is operated in urban or agricultural use, and, conditional on

$2 \quad$ There is a model that is intermediate between the durable and non-durable structure models. Property owners may irreversibly add storeys to their buildings, as is done in desert climates. 
being operated in urban use, also determines the structural density.

Let $q^{\#}$ denote the quality of land at which the landowner is indifferent between operating his land in urban and agricultural use. It is given implicitly by the equation

$$
U\left(q^{\#}\right)=R\left(q^{\#}\right)
$$

Where $q$ represents agricultural fertility, we have that land of quality higher than $q^{\#}$ is operated in agriculture and that land of quality lower than $q^{\#}$ is operated in urban use. Where higher $q$ corresponds to better amenities, corresponding to which is a higher urban rent or to reduced land preparation and construction costs, we have the opposite result.

To make operational the concept of development time in this model, we assume, as we did with the durable housing model, that urban rents grow faster than the agricultural rent, and we define development time to be the first time at which a parcel of land is operated in urban use. Then, where $q$ represents agricultural fertility, we have that higherquality land is developed later. And where higher $q$ corresponds to better amenities or to reduced construction costs, we have that higher quality land is developed earlier.

Finally, we generate results relating profit-maximizing structural density, conditional on land being more profitably employed in urban use, to land quality, by differentiating (21):

$$
\frac{d s^{*}(q)}{d q}=\frac{S_{s q}\left(s^{*}, q\right)-r C_{s} q\left(s^{*}, q\right)}{S_{s s}\left(s^{*}, q\right)-C_{s s}\left(s^{*}, q\right)} .
$$

We assume that there is increasing marginal cost to structural density. Then:

- Where higher-quality land corresponds to greater agricultural fertility, $d s^{*}(q) / d q=0$.

- Where higher-quality land corresponds to lower land preparation costs, which are interpreted as a lower fixed cost of construction, $d s^{*}(q) / d q=0$.

- Where higher-quality land corresponds to improved amenities, $d s^{*}(q) / d q>0$.

- Where higher-quality land corresponds to lower marginal construction costs, $d s^{*}(q) / d q>0$. 
Thus, the results from the static model are very similar to those from the dynamic model with durable housing. There are two qualitative differences however. In the static model, reduced construction costs always result in earlier development at higher structural density. This may be the outcome in the dynamic model too, but depending on the functional forms of the rentals function and the construction cost function, as well as the value of exogenous parameters, in the dynamic model earlier development at lower density is a possibility, as is later development at higher structural density. Analogously, in the static model an increase in amenities always results in earlier development at higher structural density but in the dynamic model this is only one of three qualitative outcomes.

\section{Conclusion}

This paper posed the following questions: Consider two neighboring lots at the metropolitan periphery, neither of which has yet been developed. In some dimension of "quality" (viz., agricultural fertility, the cost of preparing land for development, construction cost, and amenities), one lot has higher land quality than the other. This paper posed the questions: Which lot will be developed at higher structural density? And which lot will be developed earlier? To answer these questions, the paper applied the Arnott-Lewis model of the transition of land to urban use, in which a profit-maximizing developer decides under perfect foresight when and at what density to build a structure on his parcel of undeveloped land that will remain unchanged on the site forever. The paper also considered the same questions in the context of a "static" model in which structures are treated as non-durable, and in which urban rents grow faster than agricultural rents. This model is static in the sense that decisions are based only on current conditions. Development time is interpreted to be the first time at which it becomes more profitable to operate the land in urban than in agricultural use. The comparative static results with respect to land quality were very similar to those obtained in the dynamic model. The dynamic model gives a richer range of possible outcomes when higher quality denotes a reduction in construction costs or an increase in amenities. 
The qualitative results accord with intuition. Ceteris paribus: $i$ ) land that has a higher rent in non-urban use is developed later at higher density; ii) land whose preparation costs for urban development is lower is developed earlier at lower density; iii) depending on how higher quality perturbs the construction cost function, the land on which it is cheaper to construct may be developed sooner at lower density, sooner at higher density, or later at higher density; and $i v$ ) depending, among other things, on how higher quality perturbs the rental function, land with better amenities maybe developed sooner at lower density, sooner at higher density, or later at higher density.

\section{References}

[1] Arnott, R.J., Lewis, F. D. 1979. The transition of land to urban use. Journal of Political Economy. 87:161-169.

[2] Burchfield, M., Overman, H.G., Puga, D., Turner, M.A. 2006. Causes of sprawl: a portrait from space. The Quarterly Journal of Economics 121: 587-633.

[3] Irwin, E.G., Bockstael, N.E. 2002. Interacting agents, spatial externalities, and the endogenous evolution of land use patterns. Journal of Economic Geography. 2:31-54.

[4] Saiz, A. 2010. The geographic determinants of housing supply. Quarterly Journal of Economics 125: 1253-1296.

[5] Thorsnes, P. 1997. Consistent estimates of the elasticity of substitution between land and non-land inputs in the production of housing. Journal of Urban Economics. 42: 98-108.

[6] Zhang, H., Arnott, R.J. 2015. The aggregate value of land in the greater Los Angeles region. Working Paper \# 15-06, University of California, Riverside. 